\title{
Article
}

\section{Borrowing against the future: the response to the public consultation on the NHS bursary}

Regan, Paul John and Ball, Elaine

Available at http://clok.uclan.ac.uk/23556/

Regan, Paul John and Ball, Elaine (2018) Borrowing against the future: the response to the public consultation on the NHS bursary. British Journal of Nursing, 27 (13). pp. 746-749. ISSN 2052-2819

It is advisable to refer to the publisher's version if you intend to cite from the work. 10.12968/bjon.2018.27.13.746

For more information about UCLan's research in this area go to http://www.uclan.ac.uk/researchgroups/ and search for < name of research Group>.

For information about Research generally at UCLan please go to http://www.uclan.ac.uk/research/

All outputs in CLoK are protected by Intellectual Property Rights law, including Copyright law. Copyright, IPR and Moral Rights for the works on this site are retained by the individual authors and/or other copyright owners. Terms and conditions for use of this material are defined in the policies page.

\section{CLoK}

Central Lancashire online Knowledge www.clok.uclan.ac.uk

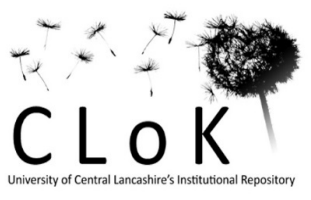




\title{
Borrowing against the future: the response to the public consultation on the NHS bursary
}

\author{
Paul Regan and Elaine Ball
}

\begin{abstract}
This paper discusses the UK government's public consultation into the NHS bursary and the response from the Nursing and Midwifery Council. A public consultation stipulated that the current arrangements for funding, by the State, were not to be considered for discussion. Instead, the consultation only appraised views that would lead to the successful introduction of student finance loans for NHS professional education. Testimonies from nurses, midwives and nursing students expressed concern that the new funding arrangements were unaffordable, dis-incentivising and biased towards the marketisation of student loans in the UK, yet the changes went ahead. The changes to NHS bursary funding resulted from the UK Government's desire for growth in student numbers (and ostensibly not growth in financial figures), and the fact that nursing (and other healthcare) students will become more fiscally indebted, despite society's moral obligation to them.
\end{abstract}

Key words: Education $\square$ Funding $\square$ Student nurses

- Workforce $\square$ Staffing $\square$ Policy

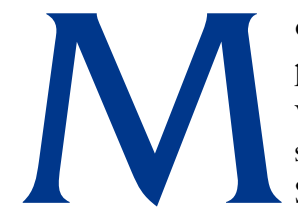

ost British nurses, midwives and allied health professionals (AHPs) reading this in 2018 will have been the grateful recipient of statutory nurse education paid for by the State. That relationship changed in 2017 with the discontinuation of the NHS bursary. The funding reforms were suggested to be necessary due to $45 \%$ of the 692773 nurses and midwives in the UK being aged 45 years and over, health worker migration globally (Kollar and Buyx, 2013), and a reduced number of European nurses migrating to the UK following the outcome of the Brexit referendum (Marangozov et al, 2016). Further influences are an increase in overseas, European and UK nurses and midwives leaving the Nursing and Midwifery Council (NMC) register and, for

Paul Regan, Senior Lecturer in Adult Nursing, University of Central Lancashire, Preston, pjregan@uclan.ac.uk

Elaine Ball, Senior Lecturer, University of Salford, Salford

Accepted for publication: May 2018 the first time, $45 \%$ of UK registrants, who make up $85 \%$ of the register, leaving between 2016 and 2017 (NMC, 2017). A contributing factor in nursing student attrition rates and poor NMC registration retention is suggested to be work-life balance, poor job satisfaction, stress and burnout, compounded by a $14 \%$ real-term fall in salaries and 1\% pay cap (Royal College of Nursing (RCN), 2016;Anim, 2017). Due to a lack of long-term strategic workforce planning, the use of costly ad hoc agency workforce and a shortage of nurses overall, the quality of care received since the Francis Report is of concern (Organisation for Economic Co-operation and Development (OECD), 2014; Marangozov et al, 2016). This phenomenon is not unique to the UK with the USA (American Association of Colleges of Nursing, 2017) and Australia also reporting nursing shortages, poor recruitment, attrition rates and retention of registered nurses, despite government subsidised training (Gilbert and Brown, 2015).

\section{Commissioned numbers}

Successive UK government's annual funding decisions have impacted on the numbers of new entrants into nurse education (NHS Business Services Authority (NHS BSA), 2016). The past quota of commissioned pre-registration and midwifery training between the year 2000 and 2016 had slightly improved since 2012 (see Table 1), however, this has not alleviated current staffing shortages due to a $10 \%$ shortfall of nurses in England (NHS BSA, 2016). Due to a systemic failure to address this issue succesfully, this paper offers a timely commentary to question the objectivity and rationale behind the funding reforms (Marangozov et al, 2016).

\section{Reasons for funding reforms}

The funding reforms published in the white paper from the Department of Health (DH) (2016a) entitled Reforming healthcare education funding:creating a sustainable future workforce documented the UK government's response to a public consultation in 2016 over 3 months involving 1743 respondents. The benefits, as suggested by the white paper, are presented in Box 1. The discontinuation of the NHS bursary was expected to affect an estimated training of 77000 nursing, midwives and AHPs (including dietetics, occupational therapy, physiotherapy, podiatry, speech and language therapy, radiotherapy, orthoptics, 
orthotics/prosthetics, operating department practitioner, dental hygienist and dental therapist) (NHS BSA, 2016). This meant dentists and medics would receive the NHS bursary only in their fifth and sixth years of training (NHS BSA, 2016). The reforms, the report suggested, would offer a more flexible approach to the constraints of previous commissioned quotas by allowing higher education institutions (HEIs) to train 10000 extra places on nursing, midwifery and AHP courses (NHS BSA, 2016; NMC, 2016). Moreover, earning a degree was suggested to lead to significant financial rewards, life-long-learning opportunities and improved graduate prospects (DH, 2016a; NMC, 2016) (Box 1).

The white paper suggested previous restrictions placed on pre-2017 funding arrangements on nurse training provision had led to prospective students' lack of success in the nurse training selection process (DH, 2016a). It referred to 2014 when 30000 or $60 \%$ of prospective students applying for nursing were not accepted onto a nurse education programme $(\mathrm{DH}$, 2016a). However, it failed to state why not all people applying for nurse training were considered appropriate to join the training provider, and the likely reasons were failing to meet the values-based criteria of the selection process (Scammel et $\mathrm{al}, 2017)$. The white paper's inference is of concern, because the nursing profession is self-regulating (under The Nursing and Midwifery Order, 2001) and has been given authorised permission to ensure the required standards for training are met for the purposes of maintaining public safety. Therefore, the selection and interviewing process by nurse lecturers and clinical nurses are best placed to identify suitable candidates, otherwise, if market driven, there is the potential for unsuitable candidates to be trained (Scammel et al, 2017).

\section{Student loans}

The introduction of student loans into higher education follows a trend in the past 30 years for higher education institutions to move away from a publicly funded training to fee-enrolment and less responsibility of the sitting government to provide fiscal responsibility for the NHS (Marangozov et al, 2016). The distancing of responsibility by a Secretary of State for Health is what the political philosopher Michael Sandel called 'markets mimicking governance', which offers a kind of political choice in settling difficult issues through the market economy, a choice that is attractive to politicians because it does not require moral debate on whether change is right or wrong (Sandel, 2009). The Labour government introduced means tested, paid up front student fees in 1998 and this paved the way to increase the burden of debt on students, rather than taxpayers, in later years (Glennerster, 2002). Hence, there is a case to be made that funding reforms are not for the common good, despite the reported benefits, and instead are profit driven, and at the expense of a student's motivation to train as a nurse J and sense of civic duty (Ziderman, 2013). In the past decade, the expansion of such an agenda has given HEIs flexibility to capitalise on a growing market (Tomlinson, 2017). This critical issue was evident in the public consultation itself by its criteria for discussion. The public consultation aimed to obtain views that would help the successful implementation
Table 1. Pre-registration nursing and midwifery places

in England

\begin{tabular}{|l|l|l|}
\hline & Nursing & Midwifery \\
\hline $2000-01$ & 19460 & 1983 \\
\hline $2001-02$ & 20668 & 2029 \\
\hline $2002-03$ & 21949 & 2250 \\
\hline $2003-04$ & 23553 & 2285 \\
\hline $2004-05$ & 24956 & 2425 \\
\hline $2005-06$ & 24520 & 2380 \\
\hline $2006-07$ & 22964 & 2170 \\
\hline $2007-08$ & 21569 & 2115 \\
\hline $2008-09$ & 21732 & 2274 \\
\hline $2009-10$ & 21337 & 2537 \\
\hline $2010-11$ & 20327 & 2493 \\
\hline $2011-12$ & 18069 & 2507 \\
\hline $2012-13$ & 17546 & 2578 \\
\hline $2013-14$ & 18056 & 2588 \\
\hline $2014-15$ & 19206 & 2563 \\
\hline $2015-16$ & 20033 & 2605 \\
\hline $5045-H b 5$ & & \\
\hline
\end{tabular}

Source: Hubble et al, 2017: 4

of funding reforms (DH, 2016a), and this led to any views held by respondents regarding a wish to maintain the old bursary, and funding provision for this sector within higher education, being dismissed on questionable grounds, for example:

\section{'A number of respondents chose not to engage with the questions, but called for maintaining the NHS bursary under the current system. Whilst these opinions have been noted, the purpose of the consultation was to invite views on the successful and fair implementation of bursary reform rather than ask about their principles and so these responses have not been considered further.'}

\section{DH, 2016a: 10}

Of course, respondents' views could be deemed to be change resistant, especially when a constructive and timely government response is required to address staffing shortages;

\section{Box 1. Suggested benefits of funding reforms}

- Enabling universities to offer up to 10000 extra training places on preregistration healthcare programmes offering students around $25 \%$ more upfront financial support while studying-for example, a single student on a 3-year programme would receive approximately $£ 2000$ more each year on a student loan compared to an NHS bursary

- Improving access to pre-registration undergraduate study for those from disadvantaged backgrounds

- Giving students with an existing qualification the chance to get funding for a second degree

Source: Department of Health, 2016a 
yet without question views in favour of NHS bursaries were ignored, which is hardly democratic. Either way, the imposition of such a limiting criterion suggests the evaluative process was biased in favour of funding reforms. The diminution of the nursing profession was further developed by the DH's impact report, which we discuss next.

\section{Impact report: no longer unique}

An impact assessment on the funding reforms from the $\mathrm{DH}$ argued that 'it is not clear why nursing, midwifery and AHP students should be treated differently' from other undergraduate students who fund the cost of their courses through an upfront loan from the Student Loans Company, a 'non-profit making government-owned organisation’ (DH, 2016b: 3-4). A fair enough question perhaps, yet one that gives rise to concern, first due to who is asking the question. The question may indicate a central underlying issue related to staffing shortages, and the recruitment, and retention of nurses, and that issue is the contract that binds society together based on equity, fairness, equal distribution of wealth (e.g. education, health services, infrastructure, the law), and the participation of citizer in public life, which are hallmarks of the healthcare professions (Rawls, 1980). Rawls (1980) suggested that people working in public service do so with a vested interest to support and shape public-services in a way that is inclusive and equitable, and as concerned citizens they are aware, more than other members of the public, of their civic duty. Hence, people previously entering public service, rather than receive fiscal gratification, (7) $1 \mathrm{~d}$ feel a sense of secial gratitude in serving and shaping putic services (Rawls, 1980). Nursing respondents in an RCN survey conducted in late 2015, however, suggested the funding reforms may instead discourage new students, especially mature ones and the reforms are seen as a high-risk strategy in a current healthcare arena seemingly ill-equipped to manage staffing shortages (RCN, 2016). The question from the DH about the uniqueness of nurses, midwives and AHPs (DH, 2016b) and tang self-funding of NHS education should be through 'a non-profit making government-owned organisation' (DH, 2016b: 4) is again misleading. First, because the impact assessment fails to acknowledge that repayments of student loans have a 3.1\% interest rate (Student Loan Company, 2017a) and second, the Sale of Student Loans Act 2008 made it legal to sell off the English student loans portfolio (SLC, 2017b). The funding reforms indicate a growth in the market to now

\section{KEY POINTS}

- A public consultation into the NHS bursary stipulated that the current arrangements for funding, by the State, were not to be considered for discussion

- Funding reforms are expected to bring flexibility to funding to 10000 student nurses, midwives and AHPs

- Rather than society being indebted to healthcare students, their fiscal debt will increase markedly

- The student loan portfolio already been sold on $\Omega$ include nurses and AHP self-funding. Hardly a reassuring detail considering discussions so far. In contrast to this, the NMC response was unequivocal.

\section{The NMCs response: uniqueness}

The NMC's (2016) response was framed within its remit as a professional regulator and the public consultation funding reforms projection of 10000 growth in nursing and midwifery students by the end of parliament. This was significant due to Health Education England's direct link of commissioning numbers to the availability of clinical placements, which would discontinue due to the funding reforms (NMC, 2016). The impact of the projected 10000 stent $\mathrm{AHP}_{s}$ is focused on the issue of quality assurance, standards of education and the availability of clinical placements to deal with this expected increase. Student nurses are unique (contrary to the previous opinion stated by the $\mathrm{DH}$ ) as unlike many of their university peers they spend $50 \%$ of their programme in a healthcare arena and the other $50 \%$ in university (DH, 2016b; Hubble et al, 2017). Their time in practice is on a rota system with irregular hours and night shifts excluding them from taking part-time work, unlike other university students (NMC, 2016). The NMC (2016) suggested that the quality of clinical placements may be reduced by an over-stretched system and that would be detrimental to mentors and the supernumerary status of nursing and midwifery students. A student failing a placement would mean extra cost added to their studies and resource implications for future placements (NMC, 2016).

The uniqueness of nursing and midwifery education was stressed by the NMC (2016) from a societal perspective and reference was made to the retention of registrants, but no mention of the issue that future students will be more indebted than ever before (RCN, 2016). Consideration should also be given (due to staff shortages) to the funding of postregistration courses such as those leading to the status of specialist community public health nurse (SCPHN), and the training of health visitors, school nurses, district nurses and practice nurses (NMC, 2016). The NMC (2016) response emphasised the need for quality education amid the expected expansion of educational providers, accessibility for students and equality by welcoming the widening participation agenda, and recruitment from local communities. The widening participation agenda refers to the government's consultation on many flexible options, such as developing the current workforce and for trusts to fund nursing degree apprenticeships, foundation degrees, and a new level of registrant, the nurse associate (Department of Health and Social Care, 2016). The NMC (2016) was also concerned about the evidence from previous funding reforms when moving from grants to loans leading to a reduction in mature students especially in the initial years of reform, which UCAS (2017) provided evidence of in 2017.

\section{UCAS end of cycle report}

The UK's higher education clearing system, UCAS, published the latest statistics and discussion in its end of cycle report for 2017. As of November 2017, UCAS reported an 18\% reduction in applications to 54985, which was 11750 fewer 
than in 2016. In 2017 UCAS reported the second highest number of acceptances, mainly 18 and 19 year olds (78\%), and a fall in mature students applying (UCAS, 2017). Between 2010 and 2016 there had been 61000-67000 applications with a $37.9-43.3 \%$ acceptance rate, which was lower than the rest of the sector (UCAS, 2017). That has changed because UCAS stated this reduction did not translate into 'an equivalently large fall in acceptance' and for 2017 'the chances of being accepted to nursing were the highest on record' (52.1\%) with 28620 acceptances (UCAS, 2017,p. 11). This would indeed indicate a more flexible approach to the selection process than in previous years, however, it is too early to comment on whether this is an improvement for the better.

\section{Conclusion}

We discussed the UK Government's public consultation on the NHS bursary and the stipulation, at the time, that the arrangements for funding by the state were not to be considered for discussion. This raised concern about the balance of the consultation, which narrowly appraised views leading to the successful introduction of student finance loans for nurse education. The consultation narrowly appraised views that would lead to the successful introduction- of student finance loans for NHS education. Given the criticism of consecutive UK governments' difficulty in project planning student nurse numbers, this only adds to poor confidence in the proposed changes. The reasons for the changes were discussed and an expected 10000 extra projected to train; yet UCAS has identified a fall in studerr nurse applications and an increased number of acceptances. The shortfall in healthcare staff remains a protracted issue and the decision to stop the NHS bursary has had the effect of furthering societies indebtedness to those in the nursing profession and AHPs, while, conversely, increasing their individual fiscal debt. How this can be morally right remains to be seen.BJN

\section{Declaration of interest: none}

American Association of Colleges of Nursing. Fact sheet: Nursing shortage. 2017. http://tinyurl.com/ybprgkd3 (accessed 26 June 2018)

Anim C. The Government's decision hurts nursing staff and the excellent patient care they are desperately trying to uphold. Royal College of Nursing. Blog, 28 March 2017. http://tinyurl.com/y86z94oe (accessed 26 June 2018)

Department of Health. Reforming healthcare education funding: creating a sustainable future workforce. Government response to public consultation. 2016a. http://tinyurl.com/ydb55w98 (accessed 26 June 2018)

Department of Health. Reforms to funding and financial support for nursing, midwifery and AHP Bursary students (SR 2015). Impact assessment DH2004. 2016b. http://tinyurl.com/yadhmrn3 (accessed 26 June 2018)

Department of Health and Social Care. New nursing degree apprenticeship (news story). 30 November 2016. http://tinyurl.com/k9lqbpv (accessed 2 July 2018)

Dixon J. NHS funding in England: money's too tight to mention. BMJ. 2016; 354: i4204. https://doi.org/10.1136/bmj.i4204

Gilbert J, Brown L. The clinical environment—do student nurses belong? A review of Australian literature. Australian Journal of Advanced Nursing. 2015; 33(1): 23-28. http://www.ajan.com.au/Vol33/Issue1/3Gilbert.pdf

Glennerster H. United Kingdom Education 1997-2001. Oxford Review of Economic Policy. 2002; 18(2): 120-136. https://doi.org/10.1093/ oxrep/18.2.120

Hubble S, Foster D, Bolton P. Reform of support for healthcare students in England. Commons Briefing Paper 7436. House of Commons Library; 2017. http://tinyurl.com/y8h6g8k8 (accessed 26 June 2018)

Kollar E, Buyx A. Ethics and policy of medical brain drain: a review. Swiss Med Wkly. 2013;143:w13845. https://doi.org/10.4414/smw.2013.13845

Marangozov R, Williams M, Buchan J. The labour market for nurses in the UK and its relationship to the demand for, and supply of international nurses in the NHS: Final report. Institute for Employment Studies; 2016. http://tinyurl.com/yb6mh5rr (accessed 26 June 2018)

NHS Business Services Authority.Your guide to NHS Student Bursaries 2016/17. 2016. http://tinyurl.com/yb9sko5z (accessed 26 June 2018)

Nursing and Midwifery Council. NMC response to Department of Health consultation 'Reforming healthcare education funding: Creating a sustainable future workforce.' 2016. http://tinyurl.com/y9v4qnj3

Nursing and Midwifery Council. The NMC register 2012/13 - 2016/17. 2017. http://tinyurl.com/y928vjrv (accessed 26 June 2018)

Organisation for Economic Co-operation and Development. OECD health statistics 2014: How does the United Kingdom Compare? Briefing Note. 2014

Rawls J. Kantian constructivism in moral theory. The Journal of Philosophy. 1980; 77(9): 515-572

Royal College of Nursing. Responses to student bursaries collected by contributors during November and December 2015. 2016. http://tinyurl. com/y8x9bt2o (accessed 26 June 2018)

Sandel M. A new politics of the common good. Episode 4 of A new citizenship (The Reith Lectures 2009). BBC Radio 4, 4 July 2009. www. bbc.co.uk/programmes/b00lb6bt (accessed 26 June 2018)

Scammell J, Tait D, White S, Tait M. Challenging nurse student selection policy: using a lifeworld approach to explore the link between care experience and student values. Nurs Open. 2017;4(4):218-229. https:// doi.org/10.1002/nop2.88

Student Loans Company. Interest rates (for undergraduate loans and postgraduate loans, until 31 August 2018). 2017a. http://tinyurl.com/ yblmstez (accessed 26 June 2018)

Student Loans Company. ICR debt sale. 2017b. http://tinyurl.com/ybrbwgqo (accessed 2 Juoy 2018)

Tomlinson M. Student perceptions of themselves as 'consumers' of higher education. British Journal of Sociology of Education. 2017;38(4):450-467. https://doi.org/10.1080/01425692.2015.11138566

UCAS. End of cycle report 2017: patterns by subject. 2017. http://tinyurl. com/y9dgcrv7 (accessed 26 June 2018).

Ziderman A. Student loan schemes in practice: a global perspective. In: Heller DE, Callender C, eds. Student financing of higher education: a comparative perspective. Abingdon: Routledge; 2013

\section{CPD reflective questions}

- What are the pros and cons of removing the NHS student bursary?

- What are the ethical and moral implications for the marketisation of the NHS and in this case the marketisation of the student loan portfolio? 